\title{
Mortality and quality of life in the five years after severe sepsis
}

\author{
Brian H Cuthbertson ${ }^{1 *}$, Andrew Elders ${ }^{2}$, Sally Hall ${ }^{3}$, Jane Taylor ${ }^{3}$, Graeme MacLennan ${ }^{3}$, Fiona Mackirdy ${ }^{4}$ and \\ Simon J Mackenzie ${ }^{4,5}$, for \\ the Scottish Critical Care Trials Group and the Scottish Intensive Care Society Audit Group
}

\begin{abstract}
Introduction: Severe sepsis is associated with high levels of morbidity and mortality, placing a high burden on healthcare resources. We aimed to study outcomes in the five years after severe sepsis.

Methods: This was a cohort study using data from a prospective audit in 26 adult ICUs in Scotland. Mortality was measured using clinical databases and quality of life using Short Form 36 (SF-36) at 3.5 and 5 years after severe sepsis.

Results: A total of 439 patients were recruited with a $58 \%$ mortality at 3.5 years and $61 \%$ mortality at 5 years. A total of 85 and 67 patients responded at 3.5 and 5 years follow-up, respectively. SF-36 physical component score (PCS) was low compared to population controls at 3.5 years (mean 41.8 (SD 11.8)) and at 5 years (mean 44.8 (SD 12.7)). SF-36 mental component score (MCS) was slightly lower than population controls at 3.5 years (mean 47.7 (SD 14.6)) and at 5 years after severe sepsis (mean 48.8 (SD 12.6)). The majority of patients were satisfied with their current quality of life (QOL) (80\%) and all patients would be willing to be treated in an ICU again if they become critically ill despite many having unpleasant memories (19\%) and recall (29\%) of ICU events.

Conclusions: Patients with severe sepsis have a high ongoing mortality after severe sepsis. They also have a significantly lower physical QOL compared to population norms but mental QOL scores were only slightly below population norms up to five years after severe sepsis. All survivors would be willing to be treated in an ICU again if critically ill. Mortality and QOL outcomes were broadly similar to other critically ill cohorts throughout the five years of follow-up.
\end{abstract}

\section{Introduction}

Severe sepsis is an increasingly common condition that is associated with high levels of morbidity and mortality as well as placing a large burden upon healthcare resources throughout the world [1-4]. The morbidity and mortality from sepsis remain high [2-4]. For those who survive severe sepsis, many will develop complications associated with significant long-term sequelae [5-11]. Perhaps unsurprisingly, health related quality of life (QOL) and activities of daily living (ADL) are frequently significantly diminished [5-12].

\footnotetext{
* Correspondence: brian.cuthbertson@sunnybrook.ca 'Department of Critical Care Medicine, Sunnybrook Health Sciences Centre, Bayview Avenue 2075, Toronto, ON M4N 3M5, Canada Full list of author information is available at the end of the article
}

QOL is a very important outcome for patients after critical care and has been shown to be poor in all subgroups of critical illness compared to the general population at various time points [13-16]. Poor QOL leads to poor patient satisfaction and high health care resource utilization $[17,18]$. There has been little work following up patients with severe sepsis for mortality beyond three years and no work looking at changes in QOL over a five-year period. Only one study looking at ADL has followed up such patients for functional outcomes to this time point [9].

The aim of this study was to determine the mortality and QOL in patients in the five years after severe sepsis. As secondary outcomes of interest, we also wanted to study the patients' willingness to be treated in an ICU again if they become critically ill, the nature of their memories of the ICU, their satisfaction with their current QOL
Ciomed Central

() 2013 Cuthbertson et al.; licensee BioMed Central Ltd. This is an open access article distributed under the terms of the Creative Commons Attribution License (http://creativecommons.org/licenses/by/2.0), which permits unrestricted use, distribution, and reproduction in any medium, provided the original work is properly cited. 
and the impact of the index illness on their place of residence and employment status.

\section{Materials and methods}

This was a prospective cohort study of patients with severe sepsis with ethics approval granted by the Scottish multicenter research ethics committee and informed consent obtained from all patients' quality of life follow-up after three years. The ethics committee approval required the research team to make contact with patients indirectly through their parent hospital team, and first and only if the patients agreed, could the research team contact the patient. Mortality follow-up used national registry databases which are known to have an accuracy of $99 \%$.

\section{Cohort and data collection}

The study was of a prospective cohort of patients with severe sepsis collected between April and October 2003. Patients were identified as having: a.) evidence of three of four systemic inflammatory response syndrome (SIRS) criteria within the previous 24 hours, b.) confirmed or clinically strongly suspected infection, c.) two or more sepsis induced organ failures of less than 24 hours duration [19], and d.) an Acute Physiology and Chronic Health Evaluation (APACHE II) score greater than or equal to 25 based within 24 hours. Inclusion criteria were the criteria for activated protein $\mathrm{C}$ administration at the time of the study [20]. Data were collected in all 26 general adult ICUs in Scotland during the study period. Hospital mortality, ICU mortality, ICU length of stay and hospital length of stay were obtained from clinical ICU databases.

\section{QOL measures and outcomes}

Patients completed Short Form-36 (SF-36) questionnaires and euroQOL-5D (EQ-5D) by telephone survey at 3.5 and 5 years after ICU admission and the results were calculated using standard techniques [13-16,21,22]. No data points were omitted from these surveys. QOL data were presented as standard deviations as appropriate. SF-36 mental component scores (MCS) and physical component scores (PCS) were calculated using standard methods and are presented on a normalized scale with 50 being the population norm and one standard deviation representing 10 points. The co-primary outcomes were mortality and QOL at five years. Secondary outcome measures included QOL at 3.5 years after ICU discharge; ICU, hospital and 3.5 year mortality; ICU length of stay and hospital length of stay. Questions related to other aspects of their ICU experience, satisfaction with QOL and changes in employment status were also asked.

\section{Statistical analysis}

Data are presented as numbers and percentages, means and standard deviations or median and interquartile ranges as appropriate. For baseline sepsis and ICU data, numbers and percentages or median and interquartile ranges were calculated as appropriate. Differences in quality of life between 3.5 years and 5 years were compared using paired-tests.

\section{Role of the funding source}

The study sponsor and funding sources had no role in the collection, analysis and interpretation of data; in the writing of the report; and in the decision to submit the paper for publication.

\section{Results}

The flow of patients through the study is presented in Figure 1. Mortality follow-up was complete. The baseline, ICU and hospital characteristics for all groups are presented in Table 1. In summary of these data, the cohort had a median age of 58 (45 to 67), a high severity of illness (APACHE II = 23 (17 to 28); Simplified Acute Physiology Score (SAPS II) $=41$ (30 to 54)) and a low level of chronic comorbidities (median 0 ( 0 to 0 ). The subjects were $53 \%$ male and had a range of organ system dysfunctions with respiratory failure being most common (65\%). Infection was microbiologically confirmed in $35 \%$ of cases, with bronchopulmonary infection the most common source (48\%), followed by other infections (21\%) and blood infections (14\%). Gram positive infection made up 16\% and Gram negative infection (10\%) of proven infections. Further data related to the severity, site and nature of sepsis are presented in Table 2.

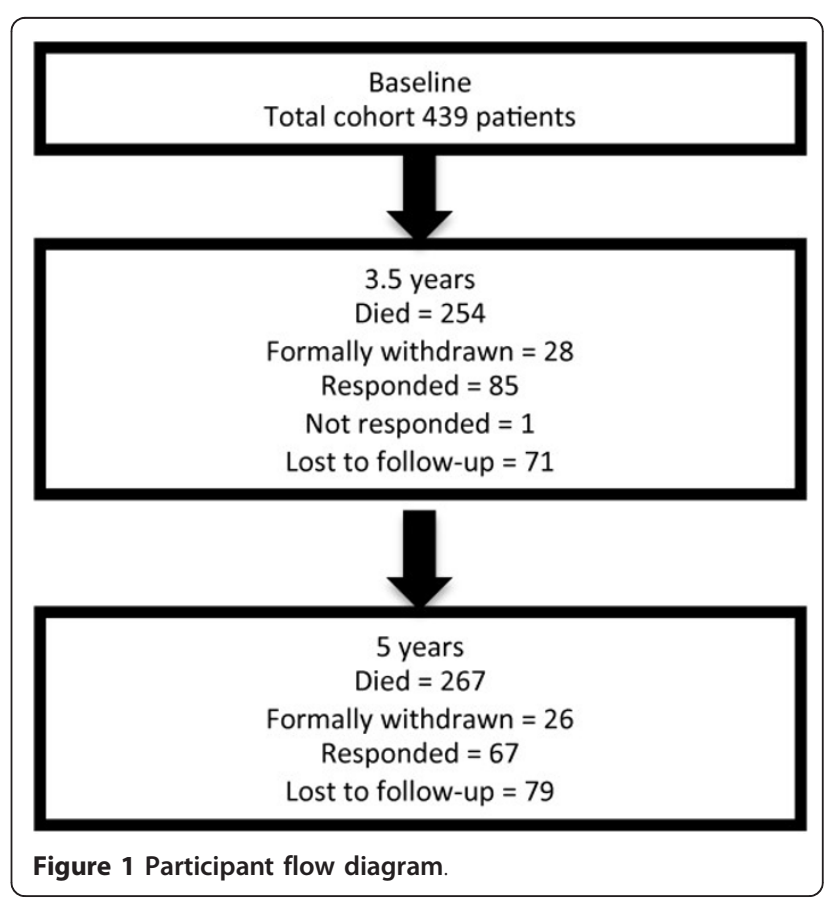


Table 1 Baseline, intensive care and hospital characteristics of study patients.

\begin{tabular}{|c|c|c|c|}
\hline & All cases & $\mathrm{N}=$ & \\
\hline & Median & $25^{\text {th }}$ & $75^{\text {th }}$ \\
\hline Age & 58.0 & 45.0 & 67.0 \\
\hline SAPS II score & 41.0 & 30.0 & 54.0 \\
\hline SAPS II predicted mortality & 26.6 & 10.6 & 55.3 \\
\hline APACHE II score & 23.0 & 17.0 & 28.0 \\
\hline APACHE II predictive mortality & 46.0 & 23.6 & 66.5 \\
\hline $\begin{array}{l}\text { Number of APACHE II comorbidities } \\
\text { (median, IQR) }\end{array}$ & 0 & 0 & 0 \\
\hline $\begin{array}{l}\text { Number of APACHE II comorbidities } \\
\text { (mean, SD) }\end{array}$ & 0.2 & 0.5 & \\
\hline Length of hospital stay prior to ICU & 1 & 0 & 3 \\
\hline ICU length of stay (all comers) & 7.1 & 2.7 & 15.8 \\
\hline $\begin{array}{l}\text { ICU length of stay (ICU survivors, } \\
\mathrm{n}=277 \text { ) }\end{array}$ & 8.8 & 3.9 & 17.9 \\
\hline $\begin{array}{l}\text { ICU length of stay (ICU non-survivors, } \\
n=162 \text { ) }\end{array}$ & 3.9 & 1.3 & 118 \\
\hline \multirow[t]{2}{*}{ Hospital length of stay } & 19.0 & 8.0 & 41.2 \\
\hline & $\mathbf{n}$ & $\%$ & \\
\hline Sex (male) & 234 & $53 \%$ & \\
\hline Readmission to ICU & 9 & $2 \%$ & \\
\hline Cardiovascular dysfunction & 237 & $54 \%$ & \\
\hline Respiratory dysfunction & 282 & $65 \%$ & \\
\hline Renal dysfunction & 166 & $38 \%$ & \\
\hline Metabolic acidosis & 195 & $45 \%$ & \\
\hline Haematological dysfunction & 100 & $23 \%$ & \\
\hline \multicolumn{4}{|l|}{ APACHE II system failure } \\
\hline Respiratory & 138 & $31 \%$ & \\
\hline Cardiovascular & 124 & $28 \%$ & \\
\hline Neurological & 44 & $10 \%$ & \\
\hline Gastrointestinal & 93 & $21 \%$ & \\
\hline Other & 26 & $7 \%$ & \\
\hline Unknown & 14 & $3 \%$ & \\
\hline Activated protein $\mathrm{C}$ administration & 94 & $21 \%$ & \\
\hline
\end{tabular}

Data presented as medians and $25^{\text {th }}$ and $75^{\text {th }}$ centiles or as number and percentages as appropriate.

The survival data show that 267 patients (63\%) survived to leave the ICU, 249 (57\%) survived to leave the hospital, 185 (42\%) survived to 3.5 years and 172 (39\%) survived to 5 years (Figure 2). Loss to follow-up occurred in 79/494 $(16 \%)$ patients. Of the 185 survivors at 3.5 years, 28 withdrew and 72 were lost to follow-up, leaving 85 responders. Of the 172 survivors at five years, 26 withdrew and 78 were lost to follow-up, leaving 67 responders.

Table 3 shows the QOL outcomes including EQ-5D and SF-36 domains and component scores. EQ-5D scores are 0.64 (SD 0.36) at 3.5 years and 0.68 (SD 0.32) at 5 years. SF-36 PCS is lower than population controls at 41.8 (SD 11.8 ) at 3.5 years and 44.8 (SD 12.7) at 5 years. SF-36 MCS is 47.7 (SD 14.6) at 3.5 years and 48.8 (SD 12.6) at 5 years.
Table 2 Data on severity, site and nature of sepsis for study patients

\begin{tabular}{lll}
\hline & All patients & $\mathbf{N}=\mathbf{4 3 9}$ \\
\hline & $\mathbf{n}$ & $\mathbf{\%}$ \\
\hline APACHE II diagnosis of sepsis & 72 & $16 \%$ \\
Microbiologically confirmed infection & 155 & $35 \%$ \\
Site of infection & & \\
Blood/bacteraemia & 63 & $14 \%$ \\
Bronchopulmonary & 211 & $48 \%$ \\
Deep wound & 43 & $10 \%$ \\
Urinary & 16 & $4 \%$ \\
Other & 91 & $21 \%$ \\
Unknown & 15 & $3 \%$ \\
Nature of infection & & \\
Bacterial - Gram positive & 69 & $16 \%$ \\
Bacterial - Gram negative & 42 & $10 \%$ \\
Mixed & 35 & $8 \%$ \\
Fungal & 6 & $1 \%$ \\
Viral & 7 & $2 \%$ \\
Unknown & 280 & $64 \%$ \\
\hline
\end{tabular}

Data presented as numbers and percentages.

At five years, the SF-36 PCS of 44.8 is significantly lower than the mean population norm of $50(P=0.001)$. The equivalent comparison for the mental component at five years shows no significant difference $(P=0.453)$.

At five years all patients stated they would be willing to be treated in an ICU again if they become critically ill, 19\% had unpleasant memories of ICU events, $80 \%$ were either very happy or mostly happy with their current QOL, with $75 \%$ either working less or not working at all compared to before their critical illness (see Table 4).

\section{Discussion}

This cohort study was designed to study mortality and QOL in the five years after ICU admission for severe sepsis and demonstrates a high mortality in this cohort of patients at this time point. The majority of this mortality occurs in hospital and within the first year but there is an ongoing attrition over the entire five-year period. This attrition has been demonstrated in other general ICU cohorts, but in sepsis cohorts follow-up has not previously been over such a long time period $[14,15,23]$. This study also demonstrates poor physical QOL scores in sepsis patients compared to age- and sex-matched population controls at 3.5 and 5 years. The QOL scores in this cohort are broadly similar to QOL scores up to five years in other cohorts of critically ill cohorts [14,15,17,24]. As has been previously demonstrated in other critically ill cohorts, mental QOL is only slightly below the age- and sexmatched population control level $[12,14,15,17,24]$. All our patients stated they would be willing to be treated in an ICU again if they become critically ill. 


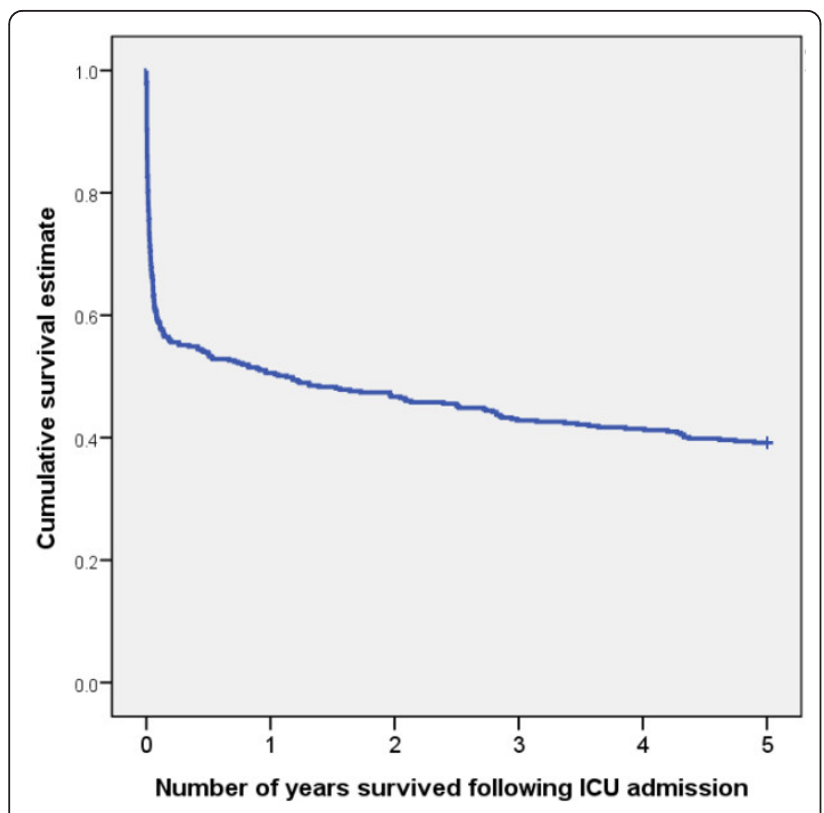

Figure 2 Kaplan-Meier survival estimates for the entire cohort.

In a landmark study, Quartin et al. followed up survivors of severe sepsis for eight years and showed an excess mortality compared to population controls [11]. Other studies have looked at survival in severe sepsis subgroups, such as community-acquired pneumonia, but find the same pattern in excess long-term mortality [25-27]. A post-hoc follow-up of patients from the PROWESS (Recombinant Human Activated Protein C Worldwide Evaluation in Severe Sepsis) study showed that the reduction in mortality seen at 28 days was lost after hospital discharge through to 3.6 years although most patients in this study were followed up for shorter durations [28]. When we compare five-year mortality data for this group, we can look at results from general ICU $[14,15,24,29]$ or acute respiratory distress syndrome
(ARDS) patients [17]. All these studies demonstrate an ongoing attrition in these cohorts with time compared to age- and sex-matched population cohorts. These results seem broadly similar to severe sepsis mortality outcomes although the younger age on ICU admission in our cohort may explain the slightly lower than expected mortality rates between 3.5 and 5 years [9,11,25-27].

There have been a few papers looking at differences in QOL outcomes in severe sepsis patients. A study by Heyland et al. suggested that SF-36 QOL scores were lower than the general population and that SF-36 had a good reliability and validity in this group [10]. A study by Hofhuis et al. showed poor QOL scores at six months after an ICU stay compared to age- and sex-matched controls [5]. A study by Granja et al. also found poor QOL in survivors of sepsis that was comparable to other non-septic critical illness survivors [30]. A study by Longo et al. studied patients receiving activated protein $\mathrm{C}$ compared to unmatched controls and looked at mortality and QOL outcome up to seven months after ICU discharge [31]. They found an $11.8 \%$ absolute risk reduction for mortality in the activated protein $C$ patients at seven months and improvements in a variety of QOL scores. This study was limited by small sample size and the lack of matching. Further studies have looked at ADL in severe sepsis survivors [9]. This study demonstrated that many severe sepsis patients have poor levels of activity (measured by ADL) in the period before severe sepsis and go on to have further functional disability in the five years after sepsis but not all of these patients are admitted to an ICU during their illness. The exact relationship between ADL and physical QOL in severe sepsis survivors is not fully understood but the information we elucidate from these metrics are likely to overlap to some degree.

The current study focuses on QOL outcomes up to five years after severe sepsis. There are no studies we have identified that studied QOL in severe sepsis patients for

Table 3 Quality of life outcomes for severe sepsis at 3.5 and 5 years

\begin{tabular}{|c|c|c|c|c|c|c|c|c|c|c|}
\hline \multirow[t]{2}{*}{ QOL metric } & \multicolumn{3}{|c|}{3.5 years } & \multicolumn{3}{|c|}{5 years } & \multicolumn{4}{|c|}{ Comparison between 3.5 and 5 years } \\
\hline & $\mathrm{N}$ & Mean & SD & $\mathrm{N}$ & Mean & SD & $\mathbf{N}$ & Mean & 95\% C.I. & $P$-value \\
\hline EQ-5D & 83 & 0.64 & 0.36 & 66 & 0.68 & 0.32 & 64 & 0.02 & $(-0.04,0.07)$ & 0.546 \\
\hline SF-36 PCS & 82 & 41.8 & 11.8 & 62 & 44.8 & 12.7 & 61 & 0.3 & $(-2.4,3)$ & 0.818 \\
\hline SF-36 MCS & 82 & 47.7 & 14.6 & 62 & 48.8 & 12.6 & 61 & 2.4 & $(0.5,4.2)$ & 0.014 \\
\hline Physical Functioning & 85 & 37.5 & 14.5 & 67 & 40.9 & 15.1 & 67 & 2.9 & $(0.9,4.9)$ & 0.005 \\
\hline Role Physical & 84 & 41.7 & 13.5 & 66 & 44.6 & 13.7 & 65 & 2.5 & $(-0.1,5.1)$ & 0.057 \\
\hline Bodily Pain & 84 & 48.0 & 12.8 & 65 & 49.9 & 11.9 & 64 & 1.1 & $(-1,3.2)$ & 0.284 \\
\hline General Health & 84 & 43.6 & 13.3 & 65 & 45.7 & 13.3 & 64 & 1.2 & $(-0.7,3.1)$ & 0.206 \\
\hline Vitality & 85 & 46.2 & 12.2 & 67 & 45.8 & 12.4 & 67 & -1.0 & $(-3.3,1.3)$ & 0.380 \\
\hline Social Functioning & 84 & 44.9 & 13.6 & 67 & 44.8 & 14.2 & 66 & -0.1 & $(-2.2,2)$ & 0.938 \\
\hline Role Emotional & 83 & 43.4 & 16.2 & 66 & 46.8 & 14.6 & 65 & 2.7 & $(-0.9,6.2)$ & 0.135 \\
\hline Mental Health & 85 & 47.0 & 13.8 & 67 & 47.6 & 13.2 & 67 & 0.3 & $(-1.8,2.5)$ & 0.764 \\
\hline
\end{tabular}

$\mathrm{Cl}$, confidence interval; MCS, mental component score; N, number; PCS, physical component score; SD, standard deviation; SF-36, short form 36. 
Table 4 Other study outcomes

\begin{tabular}{|c|c|c|c|c|}
\hline & 3.5 years & & 5 years & \\
\hline Would you be willing to be treated in an ICU again? & Valid $\mathrm{N}=74$ & & Valid $N=57$ & \\
\hline Yes & 74 & $100 \%$ & 57 & $100 \%$ \\
\hline No & 0 & $0 \%$ & 0 & $0 \%$ \\
\hline Do you have unpleasant recall of ICU events? & Valid $N=84$ & & Valid $N=66$ & \\
\hline Yes & 26 & $31 \%$ & 19 & $29 \%$ \\
\hline No & 58 & $69 \%$ & 47 & $71 \%$ \\
\hline Do you have unpleasant memories of ICU events? & Valid $\mathrm{N}=84$ & & Valid $N=67$ & \\
\hline Yes & 12 & $14 \%$ & 13 & $19 \%$ \\
\hline No & 72 & $86 \%$ & 54 & $81 \%$ \\
\hline How do you rate your satisfaction with your current QOL? & Valid $N=84$ & & Valid $N=67$ & \\
\hline Very happy & 16 & $19 \%$ & 13 & $19 \%$ \\
\hline Mostly happy & 51 & $61 \%$ & 41 & $61 \%$ \\
\hline Often unhappy & 13 & $15 \%$ & 12 & $18 \%$ \\
\hline Very unhappy & 4 & $5 \%$ & 1 & $1 \%$ \\
\hline What is your current place of residence? & Valid $N=79$ & & Valid $N=63$ & \\
\hline Private home without assistance & 62 & $79 \%$ & 49 & $78 \%$ \\
\hline Private home with assistance & 16 & $20 \%$ & 12 & $19 \%$ \\
\hline Sheltered housing & 0 & $0 \%$ & 2 & $3 \%$ \\
\hline Care home & 1 & $1 \%$ & 0 & $0 \%$ \\
\hline Other & 0 & $0 \%$ & 0 & $0 \%$ \\
\hline What is your current employment status? & Valid $N=66$ & & Valid $N=55$ & \\
\hline Full time employment / studies & 19 & $29 \%$ & 14 & $25 \%$ \\
\hline Part time employment / studies & 4 & $6 \%$ & 5 & $9 \%$ \\
\hline Occasional employment & 0 & $0 \%$ & 0 & $0 \%$ \\
\hline Retired & 29 & $44 \%$ & 24 & $44 \%$ \\
\hline Unemployed & 12 & $18 \%$ & 11 & $20 \%$ \\
\hline Long term disability & 2 & $3 \%$ & 1 & $2 \%$ \\
\hline Has your employment status changed since your illness? & Valid $N=84$ & & Valid $N=65$ & \\
\hline Yes & 19 & $23 \%$ & 12 & $18 \%$ \\
\hline No & 65 & $77 \%$ & 53 & $82 \%$ \\
\hline $\begin{array}{l}\text { If you were employed before your ICU admission, what is the intensity of } \\
\text { your current employment compared to before your illness? }\end{array}$ & Valid $N=62$ & & Valid $N=58$ & \\
\hline I work more & 14 & $13 \%$ & 7 & $0 \%$ \\
\hline No difference & 14 & $13 \%$ & 15 & $25 \%$ \\
\hline I work less & 25 & $67 \%$ & 24 & $50 \%$ \\
\hline I am not working & 9 & $7 \%$ & 12 & $25 \%$ \\
\hline
\end{tabular}

this long a time period. The most comparable studies are ones of general ICU cohorts [14,15,24] and of ARDS patients [17]. Broadly, these QOL scores are similar to those of other critically ill cohorts over this long followup [30]. It is interesting to note that the mental QOL scores are only slightly below the age- and sex-matched population control levels, which seems at odds with papers suggesting high levels of psychological morbidity and cognitive dysfunction after critical illness $[9,12$, $15,17,24,32-35]$. This may suggest a problem with the sensitivity or calibration of the SF-36 MCS in patients after critical illness since reports of depression, anxiety and post-traumatic stress disorders after severe sepsis and other critical illness seem so consistent [15,34-38].
Clearly, cognitive dysfunction is not measured in the SF36 MCS per se but it may confound the measurement of both mental and physical QOL scores.

It was very interesting to find that all our patients would be willing to undergo treatment in an ICU again if they become critically ill despite generally poor physical QOL scores and 19 to $29 \%$ having either unpleasant recall or memories of their ICU stay $[37,39,40]$. Despite the relatively poor QOL scores, the vast majority $(80 \%)$ of patients reported they were mostly or very happy with their current QOL [41]. Of course, there could be a cognitive bias in these responses as it must be difficult to state you would not want life saving treatments or that you have a poor QOL. These data also seem to somewhat contradict the 
results of previous work in acutely ill patients [40]. With regard to employment status, $34 \%$ were in full time employment at five years with $75 \%$ stating they now work less or are now not working, since their illness $[17,18,32]$. Although it must be identified that some of this reduction in employment is due to retirements. This change in employment status speaks to the broad long-term financial impact of severe sepsis on patients and their families $[15,18,42]$.

This study has a number of strengths and limitations that need to be considered. Strengths include the multicenter nature of the data and the fact that all adult general ICUs in one country were included. Further strengths include the prolonged follow-up period that has not been attained in previous studies. Compared to previous studies in this field, this is a reasonable sized study, but from an epidemiological perspective the limited patient number reduces the ability to make strong conclusions about this cohort. Limitations include the loss to follow-up in this study. The cohorts were not approached for consent for long term follow-up until well after their index ICU admission, thus denying us shorter term QOL data. The ethics committee approval required the research team to make contact with patients indirectly through their parent hospital team first and only if the patients agreed could the research team contact the patient. We believe that this additional step led to a significantly lower recruitment and retention to the study than a direct approach would have achieved. This has the potential to introduce a recruitment bias into the study data collection, although we are unable to identify the magnitude of direction of such a bias. Since it is likely that poor QOL is more common in those patients who die during follow-up, there is likely excess QOL loss to follow-up in the highest risk patients and, therefore, these QOL results may, on average, be better than those actually experienced by the patients. This issue is standard to all studies using prospective cohort designs. With regard to the generalizability of the results, we recruited patients from all adult ICU patients in one country which enhances the generalizability but we only recruited patients with an APACHE II score $\geq 25$ making this a sicker cohort than in some studies of severe sepsis. It is noted that despite the inclusion criteria for this cohort being APACHE II $\geq 25$, some patients with lower APACHE II scores were recruited to the study. In this study we demonstrated that $35 \%$ of infections were microbiologically confirmed compared to those in European Prevalence of Infection in Intensive Care (EPIC) and $60 \%$ in Sepsis Occurrence in Acutely Ill Patients (SOAP) studies [43,44]. A further limitation is the lack of pre-morbid data on physical or psychological morbidity and function $[9,34,45]$. Recent studies have identified the high level of pre-morbid physical, psychological and cognitive dysfunction in this group and that levels of these morbidities may not always be significantly higher than in the post-morbid recovery phase of critical illness $[9,34,45]$. We are, therefore, unable to confidently determine the acuity of these symptoms or their relationship to the current levels of dysfunction to the index illness in our patient group. Finally, it has been suggested by one author that QOL data should be adjusted for pre-morbid conditions, we did not do this as we believe that this is not an accepted methodological standard for QOL measurement [46].

\section{Conclusions}

Patients with severe sepsis have a high ongoing mortality after severe sepsis with only $61 \%$ surviving five years. They also have a significantly lower physical QOL compared to the population norm but mental QOL scores were only slightly below population norms up to five years after severe sepsis. Mortality and QOL outcomes were broadly similar to other critically ill cohorts throughout the five years of follow-up. These data need to be considered when evaluating longer-term outcomes and when considering the cost-effectiveness of care in this patient group.

\section{Key messages}

- Sepsis is known to have a high, shorter-term mortality; this high mortality seems to continue for up to five years after severe sepsis.

- Quality of life is known to be poor in the years after critical care admission and we have demonstrated similar patterns of QOL deficit after severe sepsis.

- The majority of severe sepsis survivors were satisfied with their current QOL and all patients would be willing to be treated in an ICU again if they become critically ill despite many having unpleasant memories and recall of ICU events.

\section{Abbreviations}

ADL, activities of daily living; APACHE II, Acute Physiology, Age And Chronic Health Evaluation; ARDS, Acute respiratory distress syndrome; EPIC, European Prevalence of Infection in Intensive Care; EQ-5D, euroQOL-5D; ICU, intensive care unit; MCS, mental component score; PCS, physical component score; QOL, quality of life; SAPS, Simplified Acute Physiology Score; SD, standard deviation; SF-36, short form 36; SIRS, systemic inflammatory response syndrome; SOAP, Sepsis Occurrence in Acutely III Patients

\section{Competing interests}

This study was funded by the Scottish Intensive Care Society and an unrestricted research grant from Eli Lilly and Company. Eli Lilly and Company did not have input into the study design or analysis and did not approve the final results. Dr Brian Cuthbertson has received honoraria for presentations and for consultancies from Eli Lilly and Company. There are no other financial or non-financial competing interests for this manuscript.

\section{Authors' contributions}

$\mathrm{BHC}, \mathrm{FM}$ and SJM have participated fully in the design of this study, the collection and analysis of data and in the writing of the paper, and have seen and approved the final version of the paper. AE and GM have 
participated fully in analysis of the data and in the writing of the paper, and have seen and approved the final version of the paper. SH and JT have participated fully in the collection of data, analysis of the data and in the writing of the paper, and have seen and approved the final version of the paper.

\section{Acknowledgements}

Brian Cuthbertson as Chief Investigator had full access to all of the data in the study and takes responsibility for the integrity of the data and the accuracy of the data analysis. The Health Services Research Unit and the Health Economics Research Unit also receive funding from the Chief Scientist Office. The views expressed in this report are those of the authors and not necessarily those of the funders.

\section{Authors' details}

${ }^{1}$ Department of Critical Care Medicine, Sunnybrook Health Sciences Centre, Bayview Avenue 2075, Toronto, ON M4N 3M5, Canada. ${ }^{2}$ Health Services Research Unit, University of Aberdeen, Health Sciences Building, Ashgrove Road, Foresterhill, Aberdeen, AB25 2ZD, Scotland, UK. ${ }^{3}$ Intensive Care Unit, Aberdeen Royal Infirmary, Westburn Road, Foresterhill, Aberdeen, AB25 2ZN, Scotland, UK. ${ }^{4}$ Scottish Intensive Care Society Audit Group, Information Services Division, NHS National Services Scotland, South Gyle Crescent 1, Edinburgh, EH12 9EB, Scotland, UK. ${ }^{5}$ Intensive Care Unit, Royal Infirmary of Edinburgh, Edinburgh, EH16 4SA, Scotland, UK.

Received: 3 October 2012 Revised: 15 February 2013

Accepted: 16 April 2013 Published: 16 April 2013

\section{References}

1. Padkin A, Goldfrad C, Brady AR, Young D, Black N, Rowan K: Epidemiology of severe sepsis occurring in the first 24 hrs in intensive care units in England, Wales, and Northern Ireland. Crit Care Med 2003, 31:2332-2338.

2. Brun-Buisson C, Doyon F, Carlet J, Dellamonica P, Gouin F, Lepoutre A, Mercier JC, Offenstadt G, Régnier B: Incidence, risk factors, and outcome of severe sepsis and septic shock in adults. A multicenter prospective study in intensive care units. French ICU Group for Severe Sepsis. JAMA 1995, 274:968-974

3. Martin GS, Mannino DM, Eaton S, Moss M: The epidemiology of sepsis in the United States from 1979 through 2000. N Engl J Med 2003, 348:1546-1554.

4. Angus DC, Linde-Zwirble WT, Lidicker J, Clermont G, Carcillo J, Pinsky MR: Epidemiology of severe sepsis in the United States: analysis of incidence, outcome, and associated costs of care. Crit Care Med 2001, 29:1303-1310.

5. Hofhuis JG, Spronk PE, van Stel HF, Schrijvers AJ, Rommes JH, Bakker J: The impact of severe sepsis on health-related quality of life: a long-term follow-up study. Anesth Analg 2008, 107:1957-1964.

6. Lindenauer PK, Rothberg MB, Nathanson BH, Pekow PS, Steingrub JS: Activated protein $\mathrm{C}$ and hospital mortality in septic shock: a propensitymatched analysis. Crit Care Med 2010, 38:1101-1107.

7. Karlsson S, Varpula M, Ruokonen E, Pettila V, Parviainen I, Ala-Kokko TI, Kolho E, Rintala EM: Incidence, treatment, and outcome of severe sepsis in ICU-treated adults in Finland: the Finnsepsis study. Intensive Care Med 2007, 33:435-443.

8. Heyland DK, Guyatt G, Cook DJ, Meade M, Juniper E, Cronin L, Gafni A: Frequency and methodologic rigor of quality-of-life assessments in the critical care literature. Crit Care Med 1998, 26:591-598.

9. Iwashyna TJ, Ely EW, Smith DM, Langa KM: Long-term cognitive impairment and functional disability among survivors of severe sepsis. JAMA 2010, 304:1787-1794.

10. Heyland DK, Hopman W, Coo H, Tranmer J, McColl MA: Long-term healthrelated quality of life in survivors of sepsis. Short Form 36: a valid and reliable measure of health-related quality of life. Crit Care Med 2000, 28:3599-3605

11. Quartin AA, Schein RM, Kett DH, Peduzzi PN: Magnitude and duration of the effect of sepsis on survival. Department of Veterans Affairs Systemic Sepsis Cooperative Studies Group. JAMA 1997, 277:1058-1063.

12. Mikkelsen ME, Christie JD, Lanken PN, Biester RC, Thompson BT, Bellamy SL, Localio AR, Demissie E, Hopkins RO, Angus DC: The adult respiratory distress syndrome cognitive outcomes study: long-term neuropsychological function in survivors of acute lung injury. Am J Respir Crit Care Med 2012, 185:1307-1315.

13. Hayes JA, Black NA, Jenkinson C, Young JD, Rowan KM, Daly K, Ridley S: Outcome measures for adult critical care: a systematic review. Health Technol Assess 2000, 4:1-111.

14. Cuthbertson BH, Scott J, Strachan M, Kilonzo M, Vale L: Quality of life before and after intensive care. Anaesthesia 2005, 60:332-339.

15. Cuthbertson BH, Roughton S, Jenkinson D, MacLennan G, Vale L: Quality of life in the five years after intensive care: a cohort study. Crit Care 2010, 14:R6

16. Chrispin PS, Scotton H, Rogers J, Lloyd D, Ridley SA: Short Form 36 in the intensive care unit: assessment of acceptability, reliability and validity of the questionnaire. Anaesthesia 1997, 52:15-23.

17. Herridge MS, Tansey CM, Matté A, Tomlinson G, Diaz-Granados N, Cooper A, Guest CB, Mazer CD, Mehta S, Stewart TE, Kudlow P, Cook D, Slutsky AS, Cheung AM, Canadian Critical Care Trials Group: Functional disability 5 years after acute respiratory distress syndrome. N Engl J Med 2011, 364:1293-1304.

18. Unroe M, Kahn JM, Carson SS, Govert JA, Martinu T, Sathy SJ, Clay AS, Chia J, Gray A, Tulsky JA, Cox CE: One-year trajectories of care and resource utilization for recipients of prolonged mechanical ventilation: a cohort study. Ann Intern Med 2010, 153:167-175.

19. Bone RC, Balk RA, Cerra FB, Dellinger RP, Fein AM, Knaus WA, Schein RM, Sibbald WJ: Definitions for sepsis and organ failure and guidelines for the use of innovative therapies in sepsis. The ACCP/SCCM Consensus Conference Committee. American College of Chest Physicians/Society of Critical Care Medicine. Chest 1992, 101:1644-1655.

20. Bernard GR, Vincent JL, Laterre PF, LaRosa SP, Dhainaut JF, LopezRodriguez A, Steingrub JS, Garber GE, Helterbrand JD, Ely EW, Fisher CJ Jr, Recombinant human protein C Worldwide Evaluation in Severe Sepsis (PROWESS) study group: Efficacy and safety of recombinant human activated protein C for severe sepsis. N Engl J Med 2001, 344:699-709.

21. Jenkinson C, Rayte R, Wright L, Coulter A: The UK SF-36: An Analysis and Interpretation Manual: a Guide to Health Status Measurement with Particular Reference to the Short Form 36 Health Survey Oxford, UK: University of Oxford Press; 1996

22. Ware JE, Kosinski M, Dewey JE: How to Score Version 2 of the SF-36 Health Survey: Standars and Acute Forms Lincoln, RI: QualityMetric, Inc.; 2001.

23. Yende S, D'Angelo G, Kellum JA, Weissfeld L, Fine J, Welch RD, Kong L, Carter $M$, Angus DC, for the GenIMS Investigators: Inflammatory markers at hospital discharge predict subsequent mortality after pneumonia and sepsis. Am J Respir Crit Care Med 2008, 177:1242-1247.

24. Graf J, Wagner J, Graf C, Koch KC, Janssens U: Five-year survival, quality of life, and individual costs of 303 consecutive medical intensive care patients - a cost-utility analysis. Crit Care Med 2005, 33:547-555.

25. Koivula I, Stén M, Mäkelä PH: Prognosis after community-acquired pneumonia in the elderly: a population-based 12-year follow-up study. Arch Intern Med 1999, 159:1550-1555.

26. Waterer GW, Kessler LA, Wunderink RG: Medium-term survival after hospitalization with community-acquired pneumonia. Am J Respir Crit Care Med 2004, 169:910-914.

27. Yende $S$, Angus DC, Ali IS, Somes G, Newman AB, Bauer D, Garcia M, Harris TB, Kritchevsky SB: Influence of comorbid conditions on long-term mortality after pneumonia in older people. J Am Geriatr Soc 2007, 55:518-525.

28. Angus DC, Laterre P-F, Helterbrand J, Ely EW, Ball DE, Garg R, Weissfeld LA, Bernard GR, PROWESS Investigators: The effect of drotrecogin alfa (activated) on long-term survival after severe sepsis. Crit Care Med 2004, 32:2199-2206.

29. Williams TA, Dobb GJ, Finn JC, Knuiman MW, Geelhoed E, Lee KY, Webb SAR: Determinants of long-term survival after intensive care. Crit Care Med 2008, 36:1523-1530.

30. Granja C, Dias C, Costa-Pereira A, Sarmento A: Quality of life of survivors from severe sepsis and septic shock may be similar to that of others who survive critical illness. Crit Care 2004, 8:R91-98.

31. Longo CJ, Heyland DK, Fisher HN, Fowler RA, Martin CM, Day AG: A long-term follow-up study investigating health-related quality of life and resource use in survivors of severe sepsis: comparison of recombinant human activated protein $\mathrm{C}$ with standard care. Crit Care 2007, 11:R128. 
32. Cuthbertson BH, Scott J, Strachan M, Kilonzo M, Vale L: Quality of life before and after intensive care. Anaesthesia 2005, 60:332-339.

33. Iwashyna TJ, Ely EW, Smith DM, Langa KM: Long-term cognitive impairment and functional disability among survivors after severe sepsis. JAMA 2010, 304:1787-1794.

34. Davydow DS, Hough CL, Langa KM, Iwashyna TJ: Symptoms of depression in survivors of severe sepsis: a prospective cohort study of older Americans. Am J Geriatr Psychiatry 2013

35. Adhikari NK, Tansey CM, McAndrews MP, Matté A, Pinto R, Cheung AM Diaz-Granados N, Herridge MS: Self-reported depressive symptoms and memory complaints in survivors five years after ARDS. Chest 2011, 140:1484-1493.

36. Griffiths J, Fortune G, Barber V, Young JD: The prevalence of post traumatic stress disorder in survivors of ICU treatment: a systematic review. Intensive Care Med 2007, 33:1506-1518.

37. Jones C, Griffiths RD, Humphris G, Skirrow PM: Memory, delusions, and the development of acute posttraumatic stress disorder-related symptoms after intensive care. Crit Care Med 2001, 29:573-580.

38. Myhren H, Ekeberg $\varnothing$, Tøien K, Karlsson S, Stokland O: Posttraumatic stress, anxiety and depression symptoms in patients during the first year post intensive care unit discharge. Crit Care 2010, 14:R14.

39. Misak CJ: The critical care experience: a patient's view. Am J Respir Crit Care Med 2004, 170:357-359.

40. Fried TR, Bradley EH, Towle VR, Allore H: Understanding the treatment preferences of seriously ill patients. N Engl J Med 2002, 346:1061-1066.

41. Hurel D, Loirat P, Saulnier F, Nicolas F, Brivet F: Quality of life 6 months after intensive care: results of a prospective multicenter study using a generic health status scale and a satisfaction scale. Intensive Care Med 1997, 23:331-337.

42. Cuthbertson BH, Campbell MK, Stott SA, Vale L, Norrie J, Kinsella J, Cook J, Brittenden J, Grant A, FOCCUS Study Group: A pragmatic multi-centre randomised controlled trial of fluid loading and level of dependency in high-risk surgical patients undergoing major elective surgery: trial protocol. Trials 2010, 11:41.

43. Vincent JL, Sakr Y, Sprung CL, Ranieri VM, Reinhart K, Gerlach H, Moreno R, Carlet J, Le Gall JR, Payen D, Sepsis Occurrence in Acutely III Patients Investigators: Sepsis in European intensive care units: results of the SOAP study. Crit Care Med 2006, 34:344-353.

44. Vincent JL, Rello J, Marshall J, Silva E, Anzueto A, Martin CD, Moreno R, Lipman J, Gomersall C, Sakr Y, Reinhart K, EPIC II Group of Investigators: International study of the prevalence and outcomes of infection in intensive care units. JAMA 2009, 302:2323-2329.

45. Iwashyna TJ, Netzer G, Langa KM, Cigolle C: Spurious inferences about long-term outcomes: the case of severe sepsis and geriatric conditions. Am J Respir Crit Care Med 2012, 185:835-841.

46. Orwelius L, Nordlund A, Nordlund P, Simonsson E, Bäckman C, Samuelsson A, Sjöberg F: Pre-existing disease: the most important factor for health related quality of life long-term after critical illness: a prospective, longitudinal, multicentre trial. Crit Care 2010, 14:R67.

doi:10.1186/cc12616

Cite this article as: Cuthbertson et al: Mortality and quality of life in the five years after severe sepsis. Critical Care 2013 17:R70.

\section{Submit your next manuscript to BioMed Central and take full advantage of:}

- Convenient online submission

- Thorough peer review

- No space constraints or color figure charges

- Immediate publication on acceptance

- Inclusion in PubMed, CAS, Scopus and Google Scholar

- Research which is freely available for redistribution

Submit your manuscript at www.biomedcentral.com/submit 